\title{
A Direct Comparison of Girls Adopted from China and Eastern Europe: Anxiety, Hyperactivity/Impulsivity, Inattention and Defiant Behaviours
}

\section{Comparación Directa de Niñas Adoptadas en China y Europa del Este: Ansiedad, Hiperactividad/Impulsividad, Inatención y Conductas Desafiantes}

\author{
Neus Abrines \\ Universidad Autónoma de Barcelona, \\ Spain \\ Diana Marre \\ Universidad Autónoma de Barcelona, \\ Spain
}

\author{
Natalia Barcons \\ Universidad Autónoma de Barcelona, \\ Spain \\ Carme Brun
}

Universidad Autónoma de Barcelona, Spain

\author{
Anke Görzig \\ University College London, \\ UK \\ Victoria Fumadó \\ Hospital Sant Joan de Déu, \\ Spain
}

\begin{abstract}
Previous research looking at adopted children has shown that children adopted from Eastern Europe (EE) are more likely to show inattention and hyperactivity/impulsivity whereas girls adopted from China $(\mathrm{CH})$ tend to have normative adjustment scores, although as they grow up, internalising behaviours might increase. We directly compare parental ratings of the SNAP-IV (Hyperactivity/Inattention) and SCARED (Anxiety) of girls adopted from $\mathrm{CH}(n=42)$, $\mathrm{EE}(n=34)$ and other countries $(n=32)$. EE were more likely to show inattention, hyperactivity/impulsivity and defiant behaviours than $\mathrm{CH}$, independent of age at adoption and number of siblings. The age of the child only had a significant effect on defiant behaviours. No significant differences in anxiety were observed between groups. Overall anxiety levels were related to hyperactivity/impulsivity. Specific factors related to adoption in each region might account for differential levels in inattention, hyperactivity/impulsivity and defiant behaviours and should be taken into account to aid the adjustment of adoptees.

Keywords: intercountry adoption, China, Eastern Europe, anxiety, inattention, hyperactivity/impulsivity, defiant behaviours.

Resumen. Estudios previos sobre menores adoptados han mostrado que los menores adoptados en Europa del Este (EE) tienen más probabilidades de mostrar inatención e hiperactividad/impulsividad mientras que las niñas adoptadas en China $(\mathrm{CH})$ suelen obtener puntuaciones normales en adaptación, aunque a medida que crecen, puede que aumenten las conductas internalizantes. Comparamos directamente las puntuaciones obtenidas en el SNAP-IV (Hiperactividad/Inatención) y el SCARED (Ansiedad) por niñas adoptadas en $\mathrm{CH}(n=42)$,
\end{abstract}

La correspondencia sobre este artìculo debe enviarse a la primera autora al e-mail: Neus.AbrinesJaume@annafreud.org 
EE $(n=34)$ y en otros países $(n=32)$. EE muestran más inatención, hiperactividad/ impulsividad y conductas desafiantes que $\mathrm{CH}$, independientemente de la edad de adopción y del número de hermanos. La edad de adopción solo tiene un efecto significativo sobre las conductas desafiantes. No se observan diferencias significativas en ansiedad entre los grupos. En general, los niveles de ansiedad están relacionados con la hiperactividad/impulsividad. Factores específicos relacionados con la adopción en cada una de estas regiones podrían explicar parte de las diferencias en inatención, hiperactividad/inatención y conductas desafiantes y se deberían tener en cuenta para potenciar la adaptación de los adoptados.

Palabras clave: adopción internacional, China, Europa del Este, ansiedad, inatención, hiperactividad/impulsividad, conductas desafiantes.

\section{Introduction}

During the last decade, the adjustment of international adoptees has become an important area of interest within the field of developmental and clinical child psychology and therefore a broad range of research is now available. The country of origin seems to be an important factor related to the postadoptive adjustment of international adoptees. However, most of the studies have either looked at mixed samples or samples of children adopted from a particular region of the world, but fewer studies have directly compared samples of children adopted from specific regions.

The two donor countries where Spanish families have been adopting most frequently during the last years are China and Russia. In Catalonia, where this study was performed, out of the 3686 children that were internationally adopted between 2007 and 2011, 1595 (43.19\%) were adopted from some Eastern European country, 1355 (36.76\%) children from Russia, and 705 (19.12\%) from China (Institut Català de l'Acolliment i de l'Adopció, 2011).

Existing literature has observed relevant differences in the adjustment and development of children coming from these two regions of the world. So far, research looking at the development of children adopted from China has observed that they seem to adjust quite easily to their adoptive families and they are not likely to show major developmental, behavioural or emotional problems. Rojewski, Shapiro, \& Shapiro, (2000) examined the behaviour of 45 children adopted from China aged between one and nine years and found that all the scales were in the average range and that age at adoption had no influence on their behaviours. However, older adoptees from this country were more likely to be rated as hyperactive or aggressive while younger adoptees were more likely to exhibit withdrawal. Tan \& Marfo (2006) examined 517 preschool and 178 school-age adopted girls and observed that Chinese adoptees were significantly better adjusted than normative US samples and preschool-age adoptees had better behavioural adjustment than school age adoptees, independent of the age at adoption. However, preadoption neglect and post-adoption initial rejection behaviours were predictors of behavioural adjustment scores. In a longitudinal follow up of this sample, Tan (2009) observed that there was a moderate to strong stability from time 1 to time 2 in the children's behavioural adjustment and academic performance but there was a significant increase in the number of children with deviant internalizing problems. At both times higher degrees of pre-adoption adversity were related to more internalising problems and poorer academic performance. Tan, Dedrick, \& Marfo, (2007) assessed the behavioural adjustment of 707 girls adopted from China and observed that while they showed similar or better behavioural adjustment than normative samples, they also tended to manifest higher levels of sleep problems. Cohen \& Farnia (2011) examined internalizing and externalizing behaviours in 70 girls adopted from China within the first month of adoption and again at 6,12 and 24 months later. Results indicated that from six months post-adoption onward, adopted children exhibited a rapid increase in emotion reactivity (internalising behaviours).

In comparison, children adopted from Eastern European countries seem to be more likely to present developmental, behavioural and/or emotional problems and therefore their adjustment to the adoptive 
family seems to be more complicated. Particularly, previous research has shown that these children are more likely to display ADHD symptoms and/or to be diagnosed with ADHD, according to parental ratings and to medication rates. Lindblad, Ringbäck Weitoft, \& Hjern (2010) conducted a national cohort study in Sweden and observed that the Eastern Europe group showed the highest rate of ADHD medication prescribed. In Minnesota, Gunnar \& Van Dulmen (2007) found that being adopted from Eastern Europe was related to the display of several behavioural disorders, such as aggressive behaviour, attention problems and social problems. According to Beverly, McGuinness \& Blanton (2008) 42\% of 55 children adopted from the former Soviet Union were diagnosed with ADHD in Columbia.

Previous to this study, Abrines, Barcons, Brun, et al. (2012) compared the scores of 93 children adopted from Eastern Europe obtained with the Swanson, Nolan, and Pelham-IV (SNAP-IV) scale with the scores of 115 children adopted from other regions. They observed that children adopted from Eastern Europe showed more ADHD symptoms than children adopted from other regions. Also, being a girl was a protective factor for the Hyperactivity/impulsivity scale and older children were more likely to show inattention.

To the best of our knowledge, three studies have directly compared children adopted from China with children adopted from Eastern European countries. Tessler, Adams, Houlihan, \& Groza (2004) compared matched samples of school-aged girls adopted from China and Romania and found that mothers with children adopted from Romania tended to report more strain in these relationships than mothers of children adopted from China. Pomerleau et al. (2005) compared the psychological development of 123 children adopted from China, East Asia and Eastern Europe and found that children adopted from Russia had a lower Mental Development Index (Bayley, 1993) than the others. Abrines, Barcons, Marre, et al., 2012) compared 24 children from Eastern Europe with 23 from China and 11 from Ethiopia and observed that children adopted from Eastern Europe showed a trend toward more hyperactivity/impulsivity and significantly more attention problems than girls adopted from China.
Several factors have been considered when trying to explain why children adopted from China present a better adjustment than children adopted from Eastern Europe, including differences in the prenatal and pre-adoptive conditions experienced by institutionalised children in these countries. Also, gender differences have been considered, as most of the children adopted from China are girls. That means that studies looking at Chinese adoptees normally look at girls whereas studies looking at children adopted from Eastern Europe normally use mixed samples. Knowing that in normative samples, girls are more likely to show internalizing symptoms whereas boys tend to present externalizing symptoms and that internalizing symptoms are less noticeable, this could partly explain why Chinese adoptees are perceived to have a better post-adoptive adjustment. Taking into account this information, the aims of this study are:

1. To directly compare girls adopted from China with girls adopted from Eastern Europe in terms of levels of anxiety, hyperactivity/ impulsivity, inattention and defiant behaviours, in order to avoid a confounding of gender between the two samples.

2. To observe the effect of socio-demographic variables (country of origin, age, age at adoption and number of siblings) on the display of anxiety, hyperactivity/impulsivity, inattention and defiant behaviours.

3. To assess the relationship between the display of anxiety and the levels of hyperactivity /impulsivity, inattention and defiant behaviours independent of the socio-demographic variables.

\section{Method}

\section{Participants}

A sample of 108 girls was recruited from the paediatric service of the Sant Joan de Déu Hospital in Barcelona. The girls were aged between 7 and 11 ( $M$ $=8.26 ; S D=1.20)$ and had been adopted at a mean age of 27.19 months $(S D=21.52)$. The sample was divided in three groups depending on the country of 
origin: 42 from China, 34 from Eastern Europe and 32 from other countries, as a comparison group (including Ethiopia, Madagascar, Colombia, Nepal, Guatemala, Mexico, India, Congo and Haiti). All girls included in the sample had been assessed by the paediatrician and did not present any nutritional deficit, infectious or parasitic disease when participating in the study. Also, children who had spent less than two years living with their adoptive family were excluded of the sample, in order to avoid the possible influence of the adaptation period.

\section{Procedure}

Invitation letters were sent to the families of adopted children aged between 7 and 10 who attended the paediatric service for regular follow-up (the participants' contact details were obtained from the data base of the hospital).

Families interested in participating contacted the research team and attended a 45 minutes appointment at the hospital offices. First of all, families were informed about the details of the procedure by a psychologist and informed consent forms were signed by the parents. Then, the parents filled in the questionnaires while the psychologist was available to clarify any concerns related to the questions. Afterwards, a psychological report with the results of the assessment was delivered to the family and, if required, treatment orientations were given. The whole sample was assessed between March 2009 and July 2010 by two psychologists.

\section{Measures}

The Screen for Child Anxiety Related Emotional Disorders - SCARED (Birmaher et al., 1997; VigilColet et al., 2009) was administered to the parents to analyse the existence of anxiety symptoms. The SCARED is a self-report questionnaire composed of 41 items and parents are asked the frequency of each symptom on a 3-point-scale: 0 (almost ever), 1 (sometimes) and 2 (often). The scale yields four first order factors related to the DSM-IV classification of anxiety disorders (Panic/somatic, Generalised anxi- ety, Separation anxiety, and Social phobia) and a second order factor of general anxiety.

The Swanson, Nolan, and Pelham-IV scale SNAP-IV (Bussing et al., 2008) was administered to the parents to analyse the display of ADHD symptoms. The SNAP IV is a scale that quantifies the presence of ADHD symptoms specified by the DSM manuals. The scale was based on the concept that the items (symptoms) in each ADHD domain describe an underlying dimension of behaviour and each item was evaluated on a 4-point scale (not at all $=0$, just a little $=1$, pretty much $=2$, and very much $=3$ ). In this study, scores from three subscales were taken into account: inattention, hyperactivity/ impulsivity, and defiant behaviours.

Finally, relevant information regarding the adoption of the child was collected using one ad hoc questionnaire. E.g: age at adoption, country of origin, number of siblings.

\section{Data analysis}

Statistical analyses were conducted using SPSS statistical software (SPSS for Windows, Rel. 19.0.0. 2010. Chicago: SPSS Inc.).

A one-way between subjects ANOVA was conducted to compare the effect of the country of origin in the levels of anxiety, hyperactivity/impulsivity, inattention and defiant behaviours in girls adopted from China, Eastern Europe and other countries.

Hierarchical multiple regression analysis were performed for all children adopted from China and Eastern Europe $(n=76)$ in order to observe the effect of demographic variables (age, age at adoption and number of siblings) on the display of total anxiety, hyperactivity/impulsivity and defiant behaviour in the first step of the analyses. Furthermore, the effect of country of origin on symptoms independent of demographics was included in a second step.

Finally, to assess the interrelations between the display of anxiety and the levels of hyperactivity/ impulsivity, inattention and defiant behaviours independent of socio-demographic characteristics, a partial correlation was performed with country of origin, age, age at adoption and number of siblings as control variables. 


\section{Results}

In the first step of the analyses standard techniques were used for the analysis of between group differences (e.g., analysis of variance with Tukey's HSD post hoc comparisons) to test whether the levels of anxiety, hyperactivity/impulsivity, inattention and deviant behaviours for adopted children would differ dependent on their country of origin as hypothesised. Socio-demographic variables (age of the child, age at adoption and number of children in the family) were also included in the analysis.

As represented in Table 1, no significant differences were observed between the three groups in terms of age of the girls or the number of children in the family. However, significant differences were observed for the age at adoption $(F(2,105)=26.58$, $p<.001)$. On average, girls adopted from China were adopted at the youngest age $(M=13.31$ months, $S D$ $=4.98)$ whereas girls adopted from other countries were adopted at the oldest age $(M=43.44$ months, $S D=21.67$ )

Regarding the SNAP-IV, there were no differences between groups in hyperactivity $(F(2,105)=$ $2.15, p=.12$ ) but differences were significant for inattention $(F(2,105)=12.27, p<.001)$ and defiant behaviours $(F(2,105)=5.64, p=.005)$. Simple comparisons revealed that girls adopted from Eastern Europe obtained significantly higher scores than girls adopted from China on both inattention [EE ( $M$ $=1.24, S D=.62)$ vs. $\mathrm{CH}(M=.55, S D=.58)]$ and defiant behaviours [EE $(M=.76, S D=.53)$ vs. $\mathrm{CH}$ $(M=.41, S D=.38)]$ (all $p$ 's <.005). In addition, in comparison to girls adopted from other countries girls adopted from Eastern Europe obtained higher scores on defiant behaviours [EE $(M=.76, S D=.53)$ vs. others $(M=.48, S D=.55)]$ while girls adopted from China were rated by their parents as showing less inattention $[\mathrm{CH}(M=.55, S D=.58)$ vs. others $(M=.94, S D=.61)]($ all $p$ 's $<.05)$

As for the scales measured by the SCARED, no significant differences were observed between any of the groups $(F$ 's $(2,105)=.4$ to 1.9 , all $p$ 's $>.15)$.

In the second step of the analysis, hierarchical multiple regression analysis were performed on total anxiety, hyperactivity/impulsivity and defiant behaviours scales for all girls adopted from China and Eastern Europe $(N=76)$, entering predictor variables in two subsequent steps (see Table 2).

Demographic variables (child age, child age at adoption, number of children in the family) were entered in Step 1 to test and control for scale differences on these variables. As showed in Table 2, the older girls are at a higher risk of presenting defiant behaviours $(\beta=.34, p<.01)$. No other significant results were observed at this first step.

Then, a dummy variable to compare adoptees from China to those from Eastern Europe (China =0)

Table 1. Between subjects ANOVA for demographic variables, SNAP-IV and SCARED by country of origin

\begin{tabular}{|c|c|c|c|c|c|}
\hline & Eastern Europe & China & Other countries & Total & Normative sample \\
\hline & $\begin{array}{l}n=34 \\
M(S D)\end{array}$ & $\begin{array}{c}n=42 \\
M(S D)\end{array}$ & $\begin{array}{c}n=32 \\
M(S D)\end{array}$ & $\begin{array}{l}n=108 \\
M(S D)\end{array}$ & \\
\hline Age of the child (years) & $8.44(1.35)$ & $8.02(1.09)$ & $8.36(1.17)$ & $8.26(1.20)$ & \\
\hline Age at adoption (months) & $29.06^{\mathrm{ab}}(22.92)$ & $13.31^{\mathrm{ab}}(4.98)$ & $43.44(21.67)$ & $27.19(21.52)$ & \\
\hline $\begin{array}{l}\text { Number of children in the family } \\
\text { SNAP }\end{array}$ & $1.94(.89)$ & $1.81(.80)$ & $2.12(.86)$ & $1.94(.85)$ & \\
\hline Hyperactivity/Impulsivity & $.85(.59)$ & $.58(.45)$ & $.70(.61)$ & $.70(.55)$ & $.50(.52)$ \\
\hline Inattention $* * *$ & $1.24^{\mathrm{a}}(.62)$ & $.55^{\mathrm{ab}}(.58)$ & $.94(.61)$ & $.88(.66)$ & $.52(.64)$ \\
\hline Defiant behaviours $* *$ & $.76^{\mathrm{ab}}(.53)$ & $.41^{\mathrm{a}}(.38)$ & $.48(.55)$ & $.54(.50)$ & $.45(.65)$ \\
\hline \multicolumn{6}{|l|}{ SCARED } \\
\hline Panic disorder & $2.26(2.45)$ & $1.52(1.49)$ & $1.47(1.69)$ & $1.74(1.91)$ & $4.10(3.50)$ \\
\hline Generalised anxiety & $6.21(2.47)$ & $6.55(3.58)$ & $6.13(3.63)$ & $6.31(3.26)$ & $7.61(3.31)$ \\
\hline Separation anxiety & $4.50(2.69)$ & $5.12(2.97)$ & $4.06(2.36)$ & $4.61(2.72)$ & $6.44(3.39)$ \\
\hline Social phobia & $4.85(3.10)$ & $5.21(3.49)$ & $4.50(3.57)$ & $4.89(3.38)$ & $6.31(2.86)$ \\
\hline School anxiety & $.56(.89)$ & $.38(.73)$ & $.56(.72)$ & $.49(.78)$ & \\
\hline Total Anxiety & $18.38(9.26)$ & $18.57(8.99)$ & $16.72(7.50)$ & $17.96(8.62)$ & $25.36(9.94)$ \\
\hline
\end{tabular}

Notes: Analysis of Variance F $(2,105)$ statistics is significant at $* * p<.01, * * * p<.001$

a Adoptees from Eastern Europe and China differ significantly $(p<.05)$

$\mathrm{b}$ Adoptees from Eastern Europe or China differ significantly from those of other countries $(p<.05)$ 
was entered in Step 2 to determine the effect of the country over and above the effects of demographics. As expected according to results in the previous section, girls adopted from Eastern Europe were at a higher risk than girls adopted from China of displaying inattention $(\beta=.51, p<.001)$ and defiant behaviours $(\beta=.35, p<.01)$, but not of showing more anxiety symptoms. However, when controlling for demographic variables, girls adopted from Eastern Europe are also more likely to be rated as hyperactive by their parents $(\beta=.28, p<.05)$. Effect sizes for the independent effect of country of adoption as measured by $R$-square change proved to be small to medium for defiant behaviours $\left(R_{\text {change }}^{2}=.10\right)$ and hyperactivity $\left(R_{\text {change }}^{2}=.06\right)$ and medium to large for inattention $\left(R_{\text {change }}^{2}=.20\right)$ (Cohen, 1992).

Finally, partial correlations were carried out on the full sample (i.e., girls adopted from China, Eastern Europe or other countries) to assess the interrelations between the display of anxiety and the levels of hyperactivity/impulsivity, inattention and defiant behaviours while controlling for demographics. Table 3 shows that anxiety symptoms were significantly related to hyperactivity/impulsivity $(r=.29, n=109$, $p<.01)$. On the other hand, as expected, the three subscales of the SNAP-IV showed the following significant correlations: the display of defiant behaviours was related to hyperactivity/ impulsivity $(r=$ $.51, n=109, p<.001)$ and inattention $(r=.23, n=109$, $p<.05)$ and the relation between inattention and hyperactivity/impulsivity symptoms was also significant $(r=.49, n=109, p<.001)$.

\section{Discussion}

According to our results, girls included in our sample seem to have normal levels of anxiety when compared to a normative sample (Vigil-Colet et al., 2009) and there are no differences between girls adopted from China and girls adopted from Eastern Europe. However girls adopted from Eastern Europe show more hyperactivity, inattention and defiant behaviours than girls adopted from China. These results are in tune with existing research, where groups of Chinese girls obtained the same, or even better, symptom scores (internalising and externalising) than normative samples (Rojewski et al., 2000; Tan \& Marfo, 2006; Tan et al., 2007; Tan, 2009) and children adopted from Eastern Europe showed high

Table 2. Hierarchical regressions predicting total anxiety (SCARED), inattention, hyperactivity/impulsivity and defiant behaviours

\begin{tabular}{|c|c|c|c|c|c|c|c|c|c|c|c|c|}
\hline & \multicolumn{3}{|c|}{ Anxiety } & \multicolumn{3}{|c|}{ Hyperactivity/impulsivity } & \multicolumn{3}{|c|}{ Inattention } & \multicolumn{3}{|c|}{ Defiant behaviours } \\
\hline & $\begin{array}{c}\text { Step } 1 \\
(\beta)\end{array}$ & $\begin{array}{c}\text { Step } 2 \\
(\beta)\end{array}$ & $R^{2}$ & $\begin{array}{c}\text { Step } 1 \\
(\beta)\end{array}$ & $\begin{array}{c}\text { Step } 2 \\
(\beta)\end{array}$ & $R^{2}$ & $\begin{array}{c}\text { Step } 1 \\
(\beta)\end{array}$ & $\begin{array}{c}\text { Step } 2 \\
(\beta)\end{array}$ & $R^{2}$ & $\begin{array}{c}\text { Step } 1 \\
(\beta)\end{array}$ & $\begin{array}{c}\text { Step } 2 \\
(\beta)\end{array}$ & $R^{2}$ \\
\hline Age of the child & -.02 & -.02 & & -0.10 & -0.08 & & .00 & .03 & & $.34 * *$ & $.36 * *$ & \\
\hline Age at adoption & .05 & .07 & & 0.10 & -0.04 & & .21 & -.04 & .06 & -.10 & & \\
\hline $\begin{array}{l}\text { Number of children. } \\
\text { in the family } \\
\text { Country of adoption }\end{array}$ & -.07 & $\begin{array}{l}-.07 \\
-.03\end{array}$ & $\begin{array}{l}.01 \\
.01\end{array}$ & 0.06 & $\begin{array}{l}0.05 \\
\mathbf{0 . 2 8} *\end{array}$ & .01 & $\begin{array}{l}.06 \\
.07^{a}\end{array}$ & $\begin{array}{l}.05 \\
.51 * * *\end{array}$ & $\begin{array}{l}.05 \\
.25^{b}\end{array}$ & .11 & $\begin{array}{l}.10 \\
.35 * *\end{array}$ & $\begin{array}{l}.16^{c} \\
.26^{c}\end{array}$ \\
\hline
\end{tabular}

$* p<.05, * * p<.01, * * * p<.001$

a $\mathrm{R} 2$ change is significant at $p<.05, \mathrm{~b} \mathrm{R} \mathrm{R}^{2}$ change is significant at $p<.001, \mathrm{c} \mathrm{R}^{2}$ change is significant at $p<.01$

1 Variable was dummy coded with $1=$ Eastern Europe and $0=$ China

Table 3. Correlations between levels of anxiety, inattention, hyperactivity/impulsivity and defiant behaviours $(\mathrm{n}=109)$

\begin{tabular}{llccc}
\hline & 1 & 2 & 3 & 4 \\
\hline 1.Total anxiety (SCARED) & 1.00 & & & \\
2 Hyperactivity (SNAP-IV) & $.29 * *$ & 1.00 & $.49 * * *$ & 1.00 \\
3 Inattention (SNAP-IV) & .15 & $.51^{* * *}$ & $.23 *$ & 1.00 \\
4 Defiant behaviours (SNAP-IV) & .19 & 3 & \\
\hline
\end{tabular}

Note: the correlations were carried out for those children adopted from Eastern Europe, China or other countries. Correlations were controlled for demographic characteristics: Country of adoption, Age of the child, Age at adoption and Number of children in the family.

***. Correlation is significant at the 0.001 level (2-tailed).

$* *$. Correlation is significant at the 0.01 level (2-tailed).

**. Correlation is significant at the 0.01 level (2-tailed). 
levels of aggressive behaviour, attention problems (Gunnar \& Van Dulmen, 2007), high rates of ADHD symptoms (Abrines, Barcons, Brun, et al., 2012), ADHD diagnosis (Beverly et al., 2008) and ADHD medication (Lindblad et al., 2010).

Regarding the effect of demographic variables on these results we observed, like other authors, that the age at adoption was not related to any of the behavioural adjustment scores (Abrines, Barcons, Brun,.. 2012; Tan \& Marfo, 2006). Moreover, the age of the child only had a significant influence on the display of defiant behaviours. This result was unexpected as other studies have observed that older adoptees seem to be more likely to show hyperactivity, aggressive behaviours (Rojewski et al., 2000) and inattention (Abrines, Barcons, Brun, et al., 2012) whereas younger adoptees seem to have better adjustment scores (Tan \& Marfo, 2006). Differences in the age of the children included in these samples might account for differences in the results. There might be specific life periods when children are more vulnerable to display some kind of emotional or behavioural symptoms. E.g.: Start of school years, early adolescence, etc. Further research exploring these issues would be required.

Results from this study confirmed previous studies showing don't between adoptees from Eastern Europe and China on a sample of girls only thereby suggesting that these and previous findings might not be biased due to different gender compositions between Eastern European or Chinese subsamples. Therefore, other factors explaining the differences observed between children adopted from these two regions of the world should be considered. On one hand, in Eastern European countries there is a higher rate of alcohol consumption during pregnancy by mothers of institutionalized children (Gunnar \& Van Dulmen, 2007; Miller, Chan, Tirella, \& Perrin, 2009). For example, in Sweden, Landgren, Svensson, Stromland, \& Andersson Gronlund (2010) observed that fetal alcohol spectrum disorders were identified for $52 \%$ of 71 children adopted from Eastern Europe and in Canada, Robert et al. (2009) concluded that $69 \%$ of 29 children adopted Eastern Europe showed physical parameters and/or neurological anomalies compatible with Fetal Alcohol Spectrum Disorder (FASD). Hyperactivity/ impulsivity and attention deficits are part of the symptoms that can be seen in children with FASD (Kvigne et al., 2004) and these similarities could lead to misinterpret the symptoms.

Differences in the temperament of these children have been considered as another factor that might provide partial explanation for the satisfactory behavioural adjustment of children adopted from China (Tan \& Marfo, 2006) as according to (Kagan, Kearsley, \& Zelazo, 1979), Chinese infants are temperamentally more adaptable than Caucasian infants.

Furthermore, social, cultural and/or environmental differences have also been considered. In terms of differences between the countries of origin, according to Tan et al. (2007) Chinese societal norms, child-rearing practices, and adult expectations may promote behaviours associated with typical adjustment as assessed on the Child Behavior Checklist - CBCL. Additionally, the conditions of the welfare system in China are considered to be clearly better than the conditions in the Eastern European countries (Tessler et al., 2004).

Regarding differences in the post adoptive placement, in Spain, there is a widespread (and false) belief that the medical records of all children institutionalized in the former Soviet Union are exaggerated to allow the judge to authorize an international adoption (Marre, 2007) and therefore families who decide to adopt in these countries might have an unrealistic idea of the child that they will adopt which could make them less prepared to deal with the difficulties presented by their child. Moreover, families who decide to adopt in Eastern European countries tend to see the cultural background of their children as more similar to their own than families who adopt in other countries where the physical differences are more evident, like China. Consequently they make less effort to incorporate the origin of the child in their lives (Marre, 2007).

Although our results are quite optimistic regarding the adjustment of girls adopted from China, it is important to bear in mind that two recent longitudinal studies looking at samples of Chinese adoptees have observed a significant increase in internalizing problems at a later point in time (Cohen \& Farnia, 2011; Tan, 2009). They discussed that some children may 
encounter difficulties to cope as pressures for social relationships and the cognitive demands of school increase (Cohen \& Farnia, 2011). A follow up assessment of this sample would be required in order to see if the anxiety levels remain low or increase.

Finally, in our sample, the display of hyperactivity/impulsivity is related to higher levels of anxiety. Therefore it is important to keep in mind that some hyperactivity symptoms could be expressing an increase in anxiety levels. Or, on the other hand, children who are more hyperactive and don't know how to cope with it could feel higher levels of anxiety. In any case, adoptive parents would benefit from more realistic expectations of what their child will be like and a deeper understanding of what emotional and behavioural symptoms mean for a specific child.

The main limitation of this study is that results are based only on the parents' ratings. Having ratings from others like teachers and or the child would strengthen our findings.

\section{Conclusions}

Girls adopted from Eastern Europe tend to show more inattention, hyperactivity/impulsivity and defiant behaviours than girls adopted from China, independent of the age at adoption. Although further research is required to best understand the reasons of these differences, it is important that families who are considering adopting internationally are aware of these differences. These families face a big and difficult decision when trying to choose from which country they want to adopt and it is important that they have as much information as possible in order to build realistic expectations and to be able to cope with possible difficulties in the development of their future child.

\section{Notes and Acknoldegements}

This study is included from 2008 until 2009 in the Research project MEC $R+\mathrm{D}$ SEJ 2006-2009 15286 International Adoption: social and familial inclusion of the internationally adopted children. Interdisciplinary and comparative perspectives, and from 2010 in the continuation of the same project:
National and international adoption: family, education and pertinence: interdisciplinary and comparative perspectives. (CSO2009-14763-C03-01) (Subprogram SOCI), both funded by the Spanish Ministry of Science and Innovation. We are also most grateful to all the families who have participated in the study and to the paediatric service of the Hospital Sant Joan de Déu, in Barcelona.

\section{References}

Abrines, N., Barcons, N., Brun, C., Marre, D., Sartini, C., \& Fumadó, V. (2012). Comparing ADHD symptom levels in children adopted from eastern europe and from other regions: Discussing possible factors involved. Children and Youth Services Review, In press

Abrines, N., Barcons, N., Marre, D., Brun, C., Fornieles-Deu, A., \& Fumado, V. (2012). ADHDlike symptoms and attachment in internationally adopted children. Attachment and Human Development, 14, 405-423. doi: 10.1080/14616 734.2012 .691656

Beverly, B. L., McGuinness, T. M., \& Blanton, D. J. (2008). Communication and academic challenges in early adolescence for children who have been adopted from the former Soviet Union. Language, Speech, and Hearing Services in Schools, 39, 303-313. doi:10.1044/0161-1461 (2008/029)

Birmaher, B., Khetarpal, S., Brent, D., Cully, M., Balach, L., Kaufman, J., \& McKenzie Neer, S. (1997). The screen for child anxiety related emotional disorders (SCARED): Scale construction and psychometric characteristics. Journal of the American Academy of Child and Adolescent Psychiatry, 36, 545-553.

Bussing, R., Fernandez, M., Harwood, M., Wei, H., Garvan, C. W., Eyberg, S. M., \& Swanson, J. M. (2008). Parent and teacher SNAP-IV ratings of attention deficit hyperactivity disorder symptoms: Psychometric properties and normative ratings from a school district sample. Assessment, 15, 317-328. doi:10.1177/1073191107313888

Cohen, J. (1992). A power primer. Psychological Bulletin, 112, 155-159. 
Cohen, N. J., \& Farnia, F. (2011). Social-emotional adjustment and attachment in children adopted from china: Processes and predictors of change. International Journal of Behavioral Development, 35, 67-77. doi:10.1177/0165025410371602

Gunnar, M. R., \& Van Dulmen, M. H. M. (2007). Behavior problems in postinstitutionalized internationally adopted children. Development and Psychopathology, 19, 129-148. doi:10.10170S 0954579407070071\$

Institut Català de l'Acolliment i de l'Adopció. (2011). Adopció internacional. Infants adoptats. Per països.. Retrieved from http://www.idescat. cat $/$ pub $/$ id $=$ aec\&n $=855$

Kagan, J., Kearsley, R. B., \& Zelazo, P. R. (1979). Infancy : Its place in human development. Cambridge, Mass.: Harvard University Press.

Kvigne, V. L., Leonardson, G. R., Neff-Smith, M., Brock, E., Borzelleca, J., \& Welty, T. K. (2004). Characteristics of children who have full or incomplete fetal alcohol syndrome. The Journal of Pediatrics, 145, 635-640. doi:10.1016/j.jpeds. 2004.07.015

Landgren, M., Svensson, L., Stromland, K., \& Andersson Gronlund, M. (2010). Prenatal alcohol exposure and neurodevelopmental disorders in children adopted from Eastern Europe. Pediatrics, 125, e1178-1185. doi:10.1542/peds.2009-0712

Lindblad , F., Ringbäck Weitoft, G., \& Hjern, A. (2010). ADHD in international adoptees: A national cohort study. European Child and Adolescent Psychiatry, 19, 37-44.

Marre, D. (2007). 'I want her to learn her language and maintain her culture': Transnational adoptive families' views of 'cultural origins'. In P. Wade (Ed.), Race, ethnicity and nation. perspectives from kinship and genetics (pp. 73-94). New York and Oxford: Berghahn Books.

Miller, L., Chan, W., Tirella, L., \& Perrin, E. (2009). Outcomes of children adopted from eastern europe. International Journal of Behavioral Development, 33, 289-298.

Pomerleau, A., Malcuit, G., Chicoine, J., Séguin, R., Belhumeur, C., Germain, P., . . J Jéliu, G. (2005).
Health status, cognitive and motor development of young children adopted from china, east asia, and russia across the first 6 months after adoption. International Journal of Behavioral Develop-ment, 29, 445-457. doi:10.1177/0165025050020 6257

Robert, M., Carceller, A., Domken, V., Ramos, F., Dobrescu, O., Simard, M. N., \& Gosselin, J. (2009). Physical and neurodevelopmental evaluation of children adopted from eastern europe. The Canadian Journal of Clinical Pharmacology = Journal Canadien De Pharmacologie Clinique, 16, e432-440.

Rojewski, J. W., Shapiro, S. M., \& Shapiro, M. (2000). Parental assessment of behavior in chinese adoptees during early childhood. Child Psychiatry and Human Development, 31, 79-96.

Tan, T. X. (2009). School-age adopted chinese girls' behavioral adjustment, academic performance, and social skills: Longitudinal results. American Journal of Orthopsychiatry, 79, 244-251. doi: 10.1037/a0015682

Tan, T. X., Dedrick, R. F., \& Marfo, K. (2007). Factor structure and clinical implications of child behavior Checklist/1.5-5 ratings in a sample of girls adopted from china. Journal of Pediatric Psychology, 32, 807-818. doi:10.1093/jpepsy/ jsm025

Tan, T. X., \& Marfo, K. (2006). Parental ratings of behavioral adjustment in two samples of adopted Chinese girls: Age-related versus socio-emotional correlates and predictors. Journal of Applied Developmental Psychology, 27, 14-30. doi:10. 1016/j.appdev.2005.12.004

Tessler, R., Adams, G., Houlihan, L., \& Groza, V. (2004). Mother-daughter relationships among Chinese and Romanian adoptees. International Journal of Child \& Family Welfare,7, 26-43.

Vigil-Colet, A., Canals, J., Cosí, S., Lorenzo-Seva, U., Ferrando, P. J., Hernández-Martínez, C., \& Doménech, E. (2009). The factorial structure of the 41-item version of the screen for child anxiety related emotional disorders (SCARED) in a spanish population of 8 to 12 years-old. International Journal of Clinical and Health Psychology, 9, 313-327.

Artículo recibido: 12/06/2012

Revisión recibida: 17/07/2012

Aceptado: 19/07/2012 